\title{
Determination of Antioxidant Activity and Total Tannin from Drumstick (Moringa oleifera Lam.) Leaves Using Different Solvent Extraction Methods
}

\author{
Mohammad Afzal Hossain ${ }^{1, a, *}$, Nadia Khan Disha ${ }^{1, b}$, Jahid Hasan Shourove ${ }^{1, c}$, Pappu Dey $^{1, d}$ \\ ${ }^{1}$ Department of Food Engineering and Tea Technology, Shahjalal University of Science and Technology, Sylhet-3114, Bangladesh \\ *Corresponding author
}

\section{A R T I C L E I N F O A B S T R A C T}

Research Article

This study was undertaken to estimate the antioxidant activity and total tannin content of Moringa olifera Lam. (Moringa) leaves and find a suitable extraction condition for maximum yield. Two types of solvent and three different extraction times and temperatures were experimented for extraction. Moringa leaves were oven-dried and powdered to determine the antioxidant activity in

Received : 05/11/2020

Accepted : 26/11/2020 terms of total phenolic content (TPC), ferric reducing antioxidant power (FRAP), and DPPH radical scavenging activity and total tannin content. The maximum TPC value noted in methanol extract, and it ranges from $6.46 \pm 0.34 \mathrm{~g}$ to $3.91 \pm 0.19 \mathrm{~g}$ gallic acid equivalent (GAE) $/ 100 \mathrm{~g}$ dry sample (DM). The FRAP values varied from $211.6 \pm 3.75$ to $344.13 \pm 3.26 \mathrm{mg}$ ascorbic acid equivalent (AAE)/100g DM and $166.67 \pm 2.90$ to $224.93 \pm 1.94 \mathrm{mg}$ AAE/100g DM, for methanol and ethanol

Keywords:

Moringa leaves Antioxidant activity Total tannins Solvent extraction Extraction time extract, respectively. The DPPH radical scavenging activity ranged from $46.32 \pm 1.07$ to $58.09 \pm$ $0.92 \%$ for methanol extract and $56.76 \pm 1.48 \%$ to $69.72 \pm 1.15 \%$ for ethanol extract. The total tannin content varied from $6.84 \pm 0.05$ to $10.22 \pm 1.11 \mathrm{mg}$ GAE/100 g dry sample and $6.77 \pm 0.08$ to 9.23 $\pm 0.51 \mathrm{mg} \mathrm{GAE} / 100 \mathrm{~g}$ DMfor methanol and ethanol extract, respectively. The highest antioxidant yield for methanol and ethanol extract of Moringa leaves differed for various conditions. Overall, Moringa leaves showed excellent antioxidant properties that can be commercially and domestically used.

\section{Introduction}

Moringa is a famous vegetable tree with multifunctional properties, belonging to the family Moringaceae. Among the 13 species of Moringa, Moringa oleifera Lam. is mostly used. It is usually recognized as the 'Drumstick' tree or just as 'Moringa'. Moringa is familiar as a miracle tree, a rich source of natural antioxidants, vitamins, minerals, and proteins (Saini et al., 2016). It has numerous nutritional advantages as well as disease-fighting capabilities against gastric ulcers, hay fever, skin diseases, diabetes, hypertension, bronchitis, and fatigue. Thus, it has medicinal uses in tropical and subtropical countries (Vongsak et al., 2013). This medicinal plant is native to Bangladesh, India, Pakistan, Afganistan, and also found in China, Africa, Thailand, Malaysia, and Mexico (Ghafar et al., 2010, Sodvadiya et al., 2020). A recent preclinical and clinical study evaluates that Moringa has excellent health-promoting properties against varieties of cancer (Sodvadiya et al., 2020). The incidence of chronic illnesses is gradually increasing day by day and reasons behind it may be the changes in lifestyle, diet, and greater consumption of processed foods, drinks, etc. (Ara et al., 2018). The human body evolves free radicals during physiological activities, which are unpaired electrons of different molecules (Vats and Gupta, 2018; Kaur et al., 2020). Antioxidant molecules such as polyphenols can protect these reactive metals by scavenging them, which prevents further chain reactions responsible for chronic diseases in our body (Jomova et al., 2012). Fresh fruits and leafy vegetables containing natural antioxidants give protection to the body against free radicals when consumed (Zzaman et al., 2021; Sevindik et al., 2017). The consumption of antioxidant-rich fruits and vegetables has been found to lower the risks of many chronic and degenerative diseases (Ara et al., 2018). The uses of different synthetic antioxidants are gradually increasing in the food sector. Nevertheless, artificial antioxidants viz. butylated hydroxyanisole and butylated hydroxytoluene are reported to be responsible for liver damages, carcinogenesis, and other toxicities in laboratory animals (Kaur et al., 2020). Thus, synthetic antioxidants should be replaced by some natural antioxidants as food additives. It is now necessary to investigate the cheaper source of natural antioxidants and also optimize the extraction of these bioactive compounds. 
Several previous studies were accompanied to study the antioxidant activity of natural sources like fruits, vegetables, plants, etc. (Ahmad et al, 2016; Rahman et al., 2016; Mohammed et al., 2019; Sevindik, 2019; Hossain et al., 2020; Mohammed et al., 2020; Sevindik, 2020; Hossain et al., 2021). Moringa leaves are a comparatively cheaper source of major essential nutrients and natural antioxidants that can potentially decrease malnutrition (Kunyanga, 2017). Various earlier studies reported that the Moringa is a prospective source of different bioactive compounds and it has potential activity as an antioxidant. The extraction of bioactive compounds from the plant material is regulated by numerous factors like solvents, methods, extraction time, etc. The optimal extraction protocol should be effective and efficient for large scale production (Vongsak et al., 2013). Olabode et al. (2015) reported that the extraction temperature and time affect the nutritional quality of the Moringa leaves. Very few studies are found earlier on the extraction of bioactive compounds from indigenous Moringa leaves of Bangladeshi region. The present study aims to appraise the antioxidant compounds and total tannins from native Moringa leaves. Besides, an attempt was made to maximize the antioxidant extraction by using two different solvents-methanol and ethanol at three different temperatures $\left(50,60\right.$ and $\left.70^{\circ} \mathrm{C}\right)$ and extraction times $(10,20$ and $30 \mathrm{~min}$ ).

\section{Materials and Methods}

\section{List of Chemicals}

All the chemicals used in this experiment were laboratory grades and collected from commercial suppliers. Ethanol $\left(\mathrm{C}_{2} \mathrm{H}_{6} \mathrm{OH}\right)$, methanol $\left(\mathrm{CH}_{3} \mathrm{OH}\right), 2$, 2diphenyl-1-picrylhydrazyl (DPPH), Folin- Ciocalteau phenol-reagent (FCR), sodium carbonate $\left(\mathrm{Na}_{2} \mathrm{CO}_{3}\right)$, potassium-dihydrogen phosphate $\left(\mathrm{KH}_{2} \mathrm{PO}_{4}\right)$, monobasic sodium phosphate dehydrate $\left(\mathrm{NaH}_{2} \mathrm{PO}_{4} \cdot 2 \mathrm{H}_{2} \mathrm{O}\right)$, trichloroacetic acid $\left(\mathrm{C}_{2} \mathrm{HCl}_{3} \mathrm{O}_{2}\right)$, potassium ferricyanide $\left(\mathrm{K}_{3}\left[\mathrm{Fe}(\mathrm{CN})_{6}\right]\right)$, ferric chloride $\left(\mathrm{FeCl}_{3}\right)$, standard gallic acid, standard ascorbic acid, distilled water. All the samples used in the study were purchased from SigmaAldrich (USA) and Merck (Germany).

\section{Sample Preparation}

Matured green leaves of Moringa were purchased from Modina Market, Sylhet, Bangladesh. These fresh leaves were washed properly to eliminate foreign particles. Then, they were separated from the petioles and dried in a forced convection laboratory oven (Model: OFA-32-8, Esco, Singapore) at $60^{\circ} \mathrm{C}$ for 24 hours (Vongsak et al., 2013). After that, they were grinded to make it powder using a laboratory blender (Model: 3390D40, Thomas Scientific, USA) and the powder was stored in airtight pouches until further usage. The entire research design of the study has been presented in Figure 1.

\section{Extraction of Bioactives}

The extraction was executed in three stages. At first, approximately $1 \mathrm{~g}$ of sample (dry Moringa leaf powder) was added to $10 \mathrm{~mL}$ of solvents $(80 \%$ methanol and $80 \%$ ethanol) and vortexed well. Then it was kept in a water bath (Model: 2616300, Hach, USA) at three different temperatures $\left(50,60\right.$ and $\left.70{ }^{\circ} \mathrm{C}\right)$ for three different times (10, 20 and $30 \mathrm{~min})$. Finally, the extracts were collected by using Whatman filter paper (No. 4) (Hossain et al., 2020).

Determination of the Total Phenolic Compound (TPC)

The TPC was estimated following the method of Zzaman et al. (2014) with slight modifications. Approximately $0.5 \mathrm{~mL}$ of the extract was taken in a $10 \mathrm{~mL}$ size volumetric flask. The solution was then added with 0.5 $\mathrm{mL}$ Folin-Ciocalteu reagent and shaken $(3 \mathrm{~min})$. One $\mathrm{mL}$ of $35 \%$ sodium carbonate $\left(\mathrm{Na}_{2} \mathrm{CO}_{3}\right)$ was mixed, and the solution was made up to $10 \mathrm{~mL}$ with distillate water. After $30 \mathrm{~min}$, the absorbance of the solutions' supernatant was estimated using a UV-Vis Spectrophotometer (Model1800, Shimadzu, Japan) measured at $765 \mathrm{~nm}$ against a reagent blank. Pure gallic acid (GA) was used to prepare a calibration curve. The total phenolic content was measured using the following mathematical formula:

$$
y=0.0497 x-0.0197, \text { where, } R^{2}=0.9952
$$

The results were calculated in g GAE/ $100 \mathrm{~g}$ dry sample.

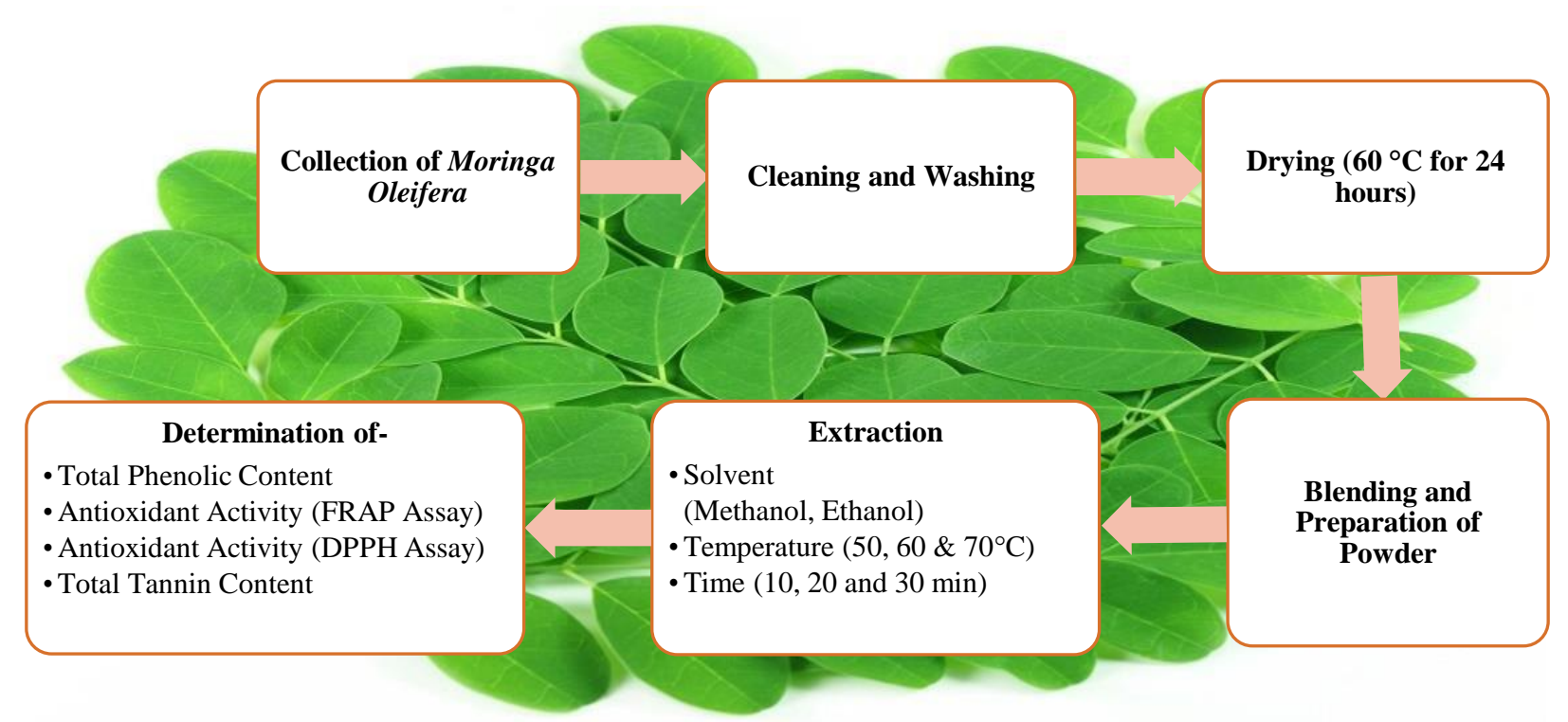

Figure 1. Schematic diagram of research design 


\section{Determination of Ferric Reducing Antioxidant Power (FRAP)}

The method described by Hossain et al. (2020) was used to estimate the ferric reducing antioxidant power of the solution. Approximately, $0.3 \mathrm{~mL}$ of the extract was mixed with $0.85 \mathrm{~mL}$ of phosphate buffer $(\mathrm{pH} 6.6,0.2 \mathrm{M})$ and $0.85 \mathrm{~mL}$ of potassium ferricyanide $(1 \%)$, and vortexed well. After incubating the mixture at $50{ }^{\circ} \mathrm{C}$ for 20 minutes, $0.85 \mathrm{~mL}$ of trichloroacetic acid $(10 \%)$ was added and vortexed. Finally, $2.85 \mathrm{ml}$ of double-distilled water and $0.57 \mathrm{~mL}$ of $\mathrm{FeC1}_{3}(1 \%)$ were mixed, and the mixture was incubated at $25^{\circ} \mathrm{C}$ for $30 \mathrm{~min}$. After that, absorbance reading was measured by using a UV-Vis Spectrophotometer (Model- 1800, Shimadzu) at $700 \mathrm{~nm}$. A blank was prepared in parallel, where distilled water was used instead of the aliquot. The standard ascorbic acid was made by serial dilution of the stock solution. Then the standard curve was made by fitting the absorbance against the corresponding concentration of the standard ascorbic solutions. The following equation was used to calculate the FRAP content of the sample:

$$
y=0.0052 x+0.0161 . \text { where, } R^{2}=0.9974
$$

The results were calculated as $\mathrm{mg}$ ascorbic acid equivalent (mg AAE/100 g DM).

\section{Determination of DPPH Radical Scavenging Activity}

The Brand-Williams (1995) method with slight modification was utilized to perform the DPPH radical scavenging assay of Moringa extract. One $\mathrm{mL}$ of aliquot was added to $4 \mathrm{~mL}$ DPPH solution in a test tube, vortexed well and allowed it in dark condition for $30 \mathrm{~min}$. Then, the absorbance reading of the mixture was taken using a UVVis Spectrophotometer (Model-1800, Shimadzu, Japan) at $517 \mathrm{~nm}$. A DPPH solution without adding the sample extract was utilized as control. The results were expressed in percentage. The following formula was used to calculate the DPPH free radical scavenging assay:

$\%$ DPPH scavenging activity $=1-$ (Absorbance of sample/Absorbance of control) $\times 100$

\section{Determination of Total Tannin Content}

The method of Amorim et al. (2008) was used to estimate the total tannin content of Moringa extract using Folin-Ciocalteu phenol reagent. At first, $0.2 \mathrm{~mL}$ of the aliquot was added with $8.3 \mathrm{~mL}$ of double-distilled water in a test tube. After that, $0.5 \mathrm{~mL}$ of Folin-Ciocalteu phenol reagent was mixed and kept for 5 min at room temperature. After incubation, $1 \mathrm{~mL}$ of sodium carbonate (35\%) solution was poured in the test tube. After shaking well, the mixture was kept for 20 minutes at $25 \pm 2^{\circ} \mathrm{C}$ temperature. Then the absorbance was taken at $725 \mathrm{~nm}$. Pure water was used to prepare a blank rather than the sample extract. A set of standard solutions of gallic acid was read against a blank. Pure gallic acid (GA) was used to prepare the calibration curve (Figure 2). The tannin content of the specimens was measured using the following standard gallic acid curve equation:

$y=0.0497 x-0.0197$, where, $R^{2}=0.9952$

The results were expressed in g GAE/ $100 \mathrm{~g}$ dry sample.

\section{Statistical Analysis}

The data were analysed using one-way ANOVA with Minitab 18 software and Excel 13. Tukey test was used to determine the significant difference $(\mathrm{P}<0.05)$. Data were expressed as means \pm standard deviation (SD) of three independent measurements.

\section{Results and Discussion}

\section{Total phenolic content}

Phenolic compounds are essential elements which help to exhibit antioxidant activity (Iqbal and Bhanger, 2006). Figure 2 represents the TPC value at different extraction conditions. It reveals methanol as a comparatively better solvent of TPC at different times and temperature ranges than the ethanol. The highest value of TPC $(6.46 \pm 0.34 \mathrm{~g}$ $\mathrm{GAE} / 100 \mathrm{~g} \mathrm{DM}$ ) was observed at $50^{\circ} \mathrm{C}$ for $30 \mathrm{~min}$ while using methanol as the solvent, and the lowest value (3.82 $\pm 0.14 \mathrm{~g}$ GAE/100 $\mathrm{g}$ DM) was found while using ethanol $\left(70^{\circ} \mathrm{C}, 10 \mathrm{~min}\right)$.

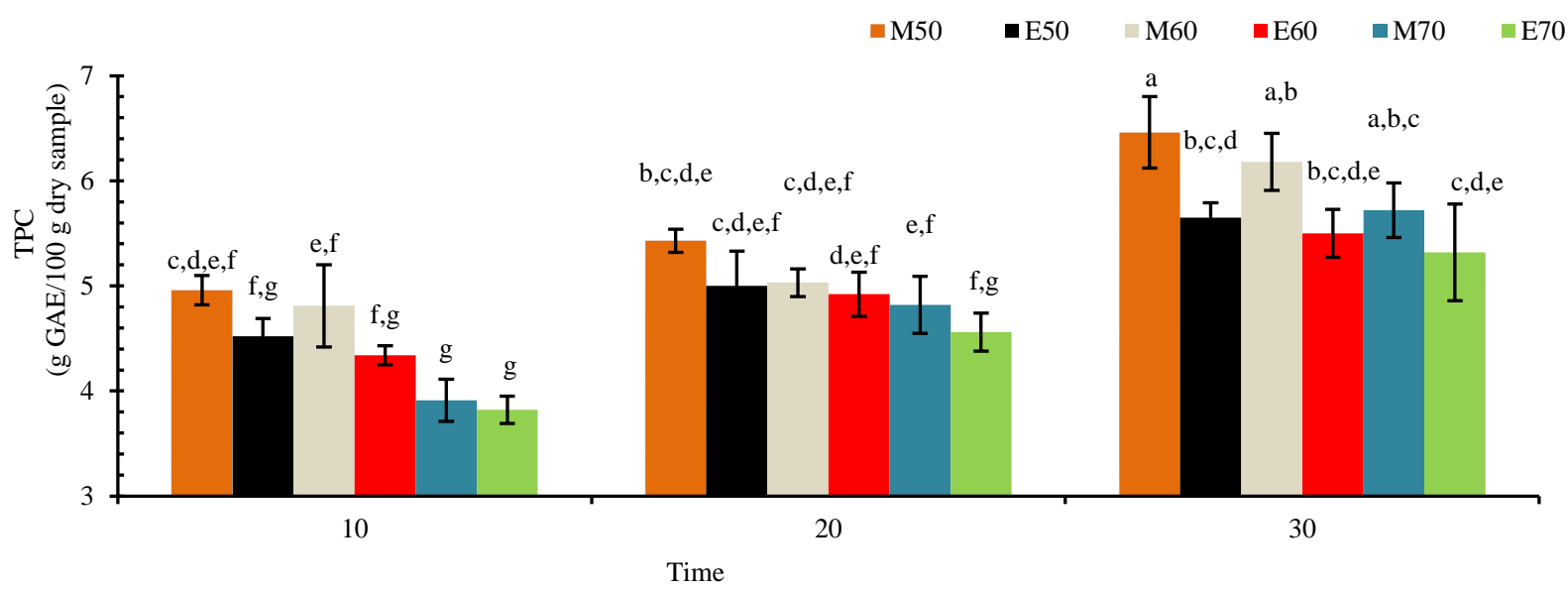

Figure 2. Effect of extraction time, temperature, and solvent on the production of TPC from the Moringa leaf extracts. Use of different superscripts within the same extraction time indicate significant differences in values $(\mathrm{P}<0.05)$ 
In most of the cases, the TPC was decreased with the increasing temperature from $50^{\circ} \mathrm{C}$ to $70^{\circ} \mathrm{C}$, and it was increased with the increasing time (10 $\mathrm{min}$ to $30 \mathrm{~min}$ ). Almost similar results were found in another study of Mokrani and Madani, (2016) who found a negative relationship with TPC and extraction temperature (25 to $70^{\circ} \mathrm{C}$ ) and positive correlation with a particular increasing time ranged from 30 to $180 \mathrm{~min}$ for peace fruit.

The highest phenolic content found in this study was higher than the TPC value $(4.54 \mathrm{~g} \mathrm{GAE} / 100 \mathrm{~g})$ found from another study by Sreelatha and Padma, (2009). According to another observation, TPC was found as $3.28 \mathrm{~g} / 100 \mathrm{~g}$ dry leaf powder (Abdulkadir et al., 2015). This difference in TPC value may be due to the difference in variety, regions, soil characteristics, extraction condition, age of the leaves (Nobossé et al., 2018). Methanol was noted as the better solvent of TPC than the ethanol in the previous study of Nobossé et al. (2018). A similar result was noted in the present study. It may be due to the variance in the polarity level of methanol (0.762) and ethanol (0.654). The compatibility of methanol and extracted polyphenolic compounds concerning polarity resulted in higher extraction (Kumari and Khatkar, 2016). A previous study reported that the increasing temperature at a certain level accelerates the extraction, but after that level, it decreased because of the reduced stability of phenolic compounds (Dorta et al., 2012). The lower TPC value was also observed at the hightemperature treatment of star fruit juice due to the destabilization of the phenolic structure (Shourove et al., 2020). The present study revealed, Moringa leaves as a potential source of polyphenol, which Moringa leaves had contained much higher total polyphenol (mg GAE/ 100g) than some Indian fruits and vegetables such as pomegranate $(671.1 \pm 18.5)$, mango $(440.6 \pm 16.6)$, kinnow $(354.9 \pm$ 12.5), banana (362.4 \pm 17.2$)$, beetroot $(909.5 \pm 37.4)$, bringal $(292.3 \pm 12.7)$, bitter gourd $(226.5 \pm 10.5)$, black carrot (1028.6 \pm 23.4$)$, spinach $(233.5 \pm 20.2)$ (Singh et al., 2016).

\section{Ferric Reducing Antioxidant Power (FRAP)}

The FRAP assay refers to the capability of the antioxidants present in moringa leaf extracts to reduce potassium ferricyanide to potassium ferrocyanide. The findings of this study have been shown in Figure 3 . According to the study, the maximum value of the ferric reducing antioxidant power was observed in methanol extracts when 30 min extraction time and $50^{\circ} \mathrm{C}$ extraction temperature were used. The minimum value was measured in ethanol extracts having $10 \mathrm{~min}$ extraction time and $70^{\circ} \mathrm{C}$ extraction temperature. The values were $344.13 \pm 3.25 \mathrm{mg}$ AAE $/ 100 \mathrm{~g}$ dry sample and $166 \pm 2.90 \mathrm{mg}$ AAE/100g dry sample, respectively. This result is similar to Nobossé et al. (2018), who found methanol extraction gave the higher value of the ferric, reducing antioxidant power than ethanol extraction. According to Tebeka and Libsu (2016), the ferric reducing antioxidant power of Moringa leaf extract was $442 \pm 10.58 \mathrm{mg}$ AAE/100g using methanol as an extraction solvent. Nobossé et al. (2018), stated that the antioxidant activity depends on the solvent of the extraction, age of the leaf and nature of the other phytochemicals present in the Moringa leaf extract. Again, Sarkar and Ghosh (2017) also found a similar result in the case of Tamarind seeds. They described that with the increase of extraction temperature from $50^{\circ} \mathrm{C}$, the value of ferric reducing assay power decrease.

\section{DPPH Radical Scavenging Activity}

The antioxidant activity of the Moringa leaves at different extraction conditions are represented in Figure 4. Significantly higher antioxidant activity $(\mathrm{P}<0.05)$ was observed in the case of ethanol solvent than methanol. The highest antioxidant activity $(69.72 \pm 1.15 \%)$ of the ethanol extract was observed at $60^{\circ} \mathrm{C}(20 \mathrm{~min})$, and the lowest value $(46.32 \pm 1.07 \%)$ was observed in methanol extract at $70^{\circ} \mathrm{C}$ (30 min). Abdulkadir et al. (2015) found the DPPH scavenging assay of Moringa leaf extract as $58.62 \%$ in the case of methanol solvent, which is in the range of our current findings. In another study, ethanol extract was found to exhibit the highest DPPH activity (53.30\%$71.10 \%$ ) (Nobossé et al., 2018). In this study, the maximum amount of antioxidant activity was observed in ethanol solvent than the methanol. It may be due to the extracted flavonoid content, chlorophyll, ascorbic acid and the structure of polyphenolic compounds. The methanol solvent is very useful for the extraction of high molecular weight polyphenol compounds and ethanol is best for the extraction of low molecular weight flavonoids from the plant matrix (Sreelatha and Padma, 2009; Nobossé et al., 2018).

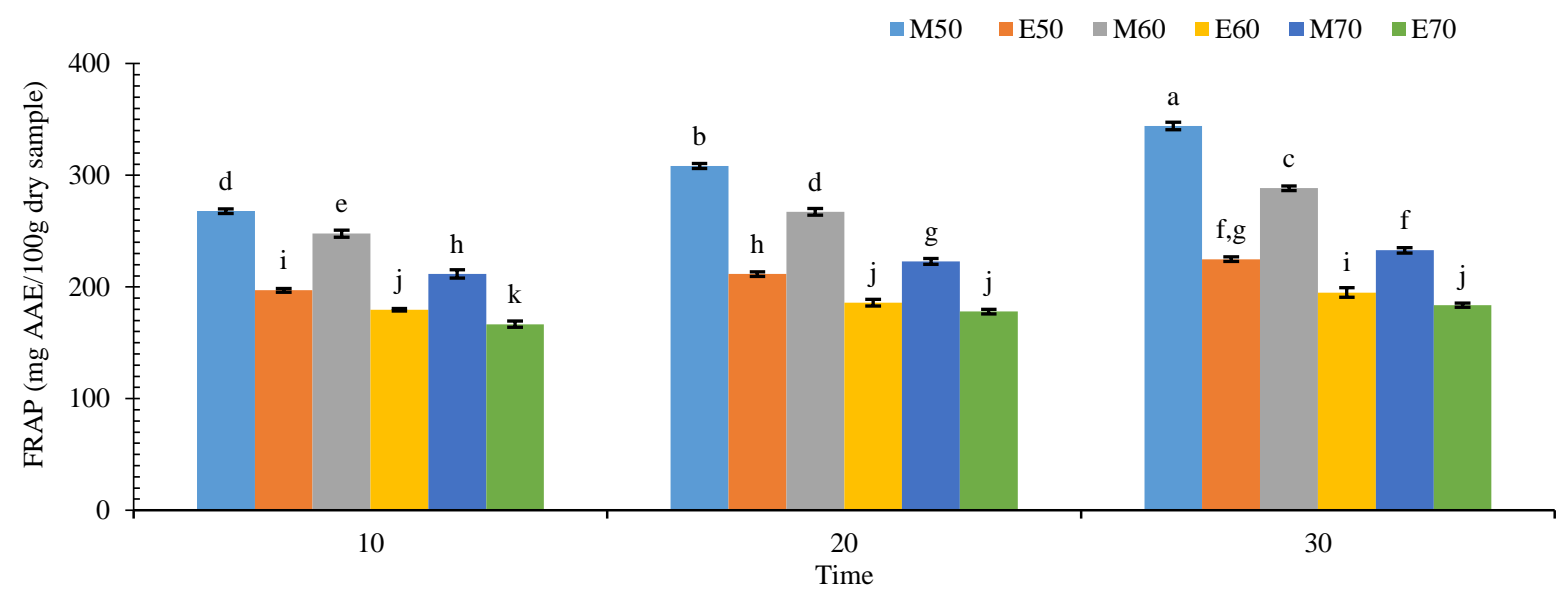

Figure 3. Effect of extraction time, temperature, and solvent on the ferric reducing antioxidant power from the Moringa leaf extracts. Use of different superscripts within the same extraction time indicate significant differences in values 


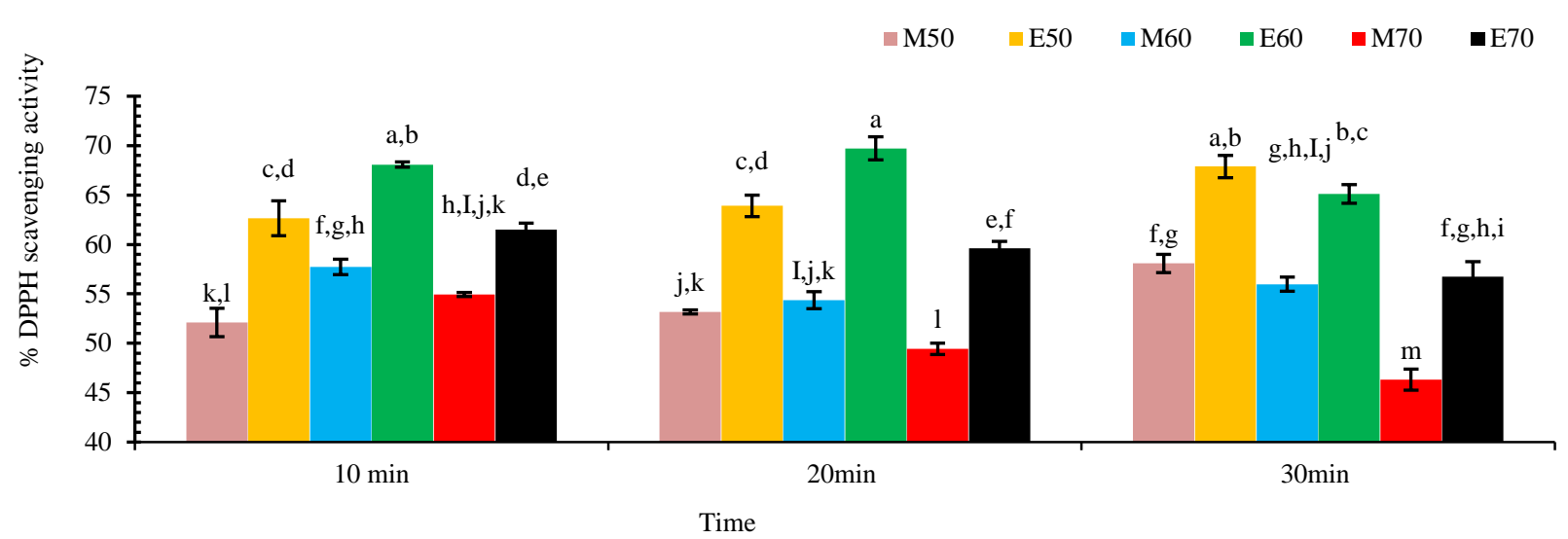

Figure 4. Effect of extraction time, temperature, and solvent on the DPPH radical scavenging activity of from the Moringa leaf extracts. Use of different superscripts within the same extraction time indicate significant differences in values $(\mathrm{P}<0.05)$.



Figure 5. Effect of extraction time, temperature, and solvent on total tannin content of the Moringa leaf extracts. Use of different superscripts within the same extraction time indicate significant differences in values $(\mathrm{P}<0.05)$.

The temperature effect was also observed on the antioxidant activity. In this study, the maximum antioxidant activity was found at $60^{\circ} \mathrm{C}$ temperature, and it may be due to the proper solubility of the flavonoid content at that condition. Again, the antioxidant value was found to decrease with the increasing temperature and the extraction time, which maybe because of the destruction of the chemical composition of the polyphenolic compounds, ascorbic acid and chlorophyll content of the Moringa leaf (Sreelatha and Padma, 2009; Nobossé et al., 2018). Those study revealed Moringa leaves as a potential source of antioxidant compounds, which showed higher antioxidant activity than some typical fruit juice such as: lemon (63\%), orange $(61 \%)$, star fruit $(60.19 \%)$, mandarin $(52 \%)$, grapefruits $(58 \%)$ (Shourove et al., 2020).

\section{Total Tannin Content (TTC)}

The TTC of plant sources consists of two groups such as hydrolyzable and condensed. Hydrolyzable tannins refer to a mixture of simple phenol having ester linkage in their structure. Again, condensed tannin refers to flavonoids with different condensation (Altemimi et al., 2017). The TTC of the Moringa leaf was measured in the present study. The results have been represented in Figure 5.
The highest value of TTC was obtained in $70^{\circ} \mathrm{C}$ methanol extraction with $30 \mathrm{~min}$ of extraction time, and the value was $10.22 \pm 1.11 \mathrm{mg}$ GAE/100 $\mathrm{g} \mathrm{DM}$. The lowest value of total tannin was measured in $50^{\circ} \mathrm{C}$ methanol and ethanol extraction with 10 min extraction time. According to Ademiluyi et al. (2018), during methanol extraction, total tannin content was $5 \pm 0.03 \mathrm{mg} \mathrm{GAE} / 100 \mathrm{~g}$ DM which was lower than our findings and might be due to the increased extraction temperature. The total tannin content of the extract was increased with the increase in extraction time and temperature. This finding is in line with the findings of Olabode et al., (2015), who stated that with the increase in extraction temperature, the total tannin content of Moringa leaf was also improved.

\section{Conclusion}

In this study, the methanol extraction with a more extended period of extraction time and minimum temperature resulted in a high value of total phenolic content and FRAP in Moring a leaf extracts. Ethanol extract with medium extraction time and temperature resulted in higher DPPH scavenging activity. In the case of tannin, total tannin content was increased with the increase of extraction time and temperature for both methanol and 
ethanol extraction. It can be concluded from the present study that methanol might be used as a better solvent to extract antioxidants from Moring a leaf and extraction time and temperature should be placed moderate. Further study can be done about developing value-added products from this Moringa leaf powder.

\section{References}

Abdulkadir AR, Zawawi DD, Jahan MS. 2015. DPPH antioxidant activity, total phenolic and total flavonoid content of different part of Drumstic tree (Moringa oleifera Lam.). Journal of Chemical and Pharmaceutical Research, 7(4):1423-28.

Ademiluyi AO, Aladeselu OH, Oboh G, Boligon AA. 2018. Drying alters the phenolic constituents, antioxidant properties, $\alpha$-amylase, and $\alpha$-glucosidase inhibitory properties of Moringa (Moringa oleifera) leaf. Food Science \& Nutrition, 6(8):2123-33. doi: 10.1002/fsn3.770

Ahmad I, Das TT, Yasin M, Hossain MA. 2016. Study on Biochemical Compounds, Antioxidant Activity and Organoleptic Taste of Some Spice Tea. Agriculture and Food Sciences Research, 3(2): 53-58. DOI: https://doi.org/ 10.20448/journal.512/2016.3.2/512.2.53.58

Altemimi A, Lakhssassi N, Baharlouei A, Watson DG, Lightfoot DA. 2017. Phytochemicals: Extraction, isolation, and identification of bioactive compounds from plant extracts. Plants, 6(4):42. DOI: https://doi.org/10.3390/plants6040042

Amorim EL, Nascimento JE, Monteiro JM, Peixoto Sobrinho TJ, Araújo TA, Albuquerque UP. 2008. A simple and accurate procedure for the determination of tannin and flavonoid levels and some applications in ethnobotany and ethnopharmacology. Functional Ecosystems and Communities, 2(1): 88-94.

Brand-Williams W, Cuvelier ME, Berset CL. Use of a free radical method to evaluate antioxidant activity. 1995. LWT-Food science and Technology, 28(1):25-30. DOI: https://doi.org/ 10.1016/S0023-6438(95)80008-5

Dorta E, Lobo MG, Gonzalez M. 2012. Reutilization of mango byproducts: study of the effect of extraction solvent and temperature on their antioxidant properties. Journal of Food Science, 77(1):C80-88. DOI: 10.1111/j.1750-3841.2011. 02477.x

Ghafar MF, Prasad KN, Weng KK, Ismail A. 2010. Flavonoid, hesperidine, total phenolic contents and antioxidant activities from Citrus species. African Journal of Biotechnology, 9(3): 326-330. DOI: https://doi.org/10.5897/AJB09.1229

Hossain MA, Evan MS, Moazzem MS, Roy M, Zzaman W. 2020. Response Surface Optimization for Antioxidant Extraction from Jackfruit (Artocarpus heterophyllus Lam.) Seed and Pulp. Journal of Scientific Research, 12(3):397-409. DOI: https://doi.org/10.3329/jsr.v12i3.44459

Hossain MA, Mitra S, Belal M, Zzaman W. 2021. Effect of foaming agent concentration and drying temperature on biochemical properties of foam mat dried Tomato powder. Food Research. 5(2), (In press).

Iqbal S, Bhanger MI. 2006. Effect of season and production location on antioxidant activity of Moringa oleifera leaves grown in Pakistan. Journal of food Composition and Analysis, 19(6-7):544-51. DOI: https://doi.org/10.1016/ j.jfca.2005.05.001

Jahan IA, Hossain MH, Ahmed KS, Sultana Z, Biswas PK, Nada K. 2018. Antioxidant activity of Moringa oleifera seed extracts. Oriental Pharmacy and Experimental Medicine, 18(4):299-307. DOI: https://doi.org/10.1007/s13596-0180333-y

Jomova K, Baros S, Valko M. 2012. Redox active metal-induced oxidative stress in biological systems. Transition Metal Chemistry, 37(2):127-34. DOI: https://doi.org/10.1007/ s11243-012-9583-6
Kaur N, Arora DS, Kalia N, Kaur M. 2020. Antibiofilm, antiproliferative, antioxidant and antimutagenic activities of an endophytic fungus Aspergillus fumigatus from Moringa oleifera. Molecular biology reports, 47(4):2901-11. DOI: https://doi.org/10.1007/s11033-020-05394-7

Kumari P, Khatkar BS. 2016. Assessment of total polyphenols, antioxidants and antimicrobial properties of aonla varieties. Journal of food science and technology, 53(7):3093-103. DOI: https://doi.org/10.1007/s13197-016-2282-0

Kunyanga CN, Imungi JK, Okoth MW, Biesalski HK, Vadivel V. 2012. Total phenolic content, antioxidant and antidiabetic properties of methanolic extract of raw and traditionally processed Kenyan indigenous food ingredients. LWT-Food Science and Technology, 45(2):269-76. DOI: https://doi.org/ 10.1016/j.lwt.2011.08.006

Mohammed FS, Daştan T, Sevindik M, Selamoglu Z. 2019. Antioxidant, antimicrobial activity and therapeutic profile of Satureja hortensis from Erzincan Province. Cumhuriyet Tip Dergisi, 41(3): 558-562.

Mohammed FS, Şabik AE, Sevindik E, Pehlivan M, Sevindik M. 2020. Determination of Antioxidant and Oxidant Potentials of Thymbra spicata Collected from Duhok-Iraq. Turkish Journal of Agriculture-Food Science and Technology, 8(5): 1171-1173.

Mokrani A, Madani K. 2016. Effect of solvent, time and temperature on the extraction of phenolic compounds and antioxidant capacity of peach (Prunus persica L.) fruit. Separation and Purification Technology, 162:68-76. DOI: https://doi.org/10.1016/j.seppur.2016.01.043

Nobossé P, Fombang EN, Mbofung CM. 2018. Effects of age and extraction solvent on phytochemical content and antioxidant activity of fresh Moringa oleifera L. leaves. Food Science \& Nutrition, 6(8):2188-98. DOI: https://doi.org/10.1002/fsn3.783

Olabode ZA, Akanbi CT, Olunlade B, Adeola AA. 2015. Effects of drying temperature on the nutrients of Moringa (Moringa oleifera) leaves and sensory attributes of dried leaves infusion. Direct Research Journal of Agriculture and Food Science, 3(5):177-22.

Rahman MM, Khan FE, Das R, Hossain MA. 2016. Antioxidant activity and total phenolic content of some indigenous fruits of Bangladesh. International Food Research Journal, 23(6):2399-2404

Saini RK, Sivanesan I, Keum YS. 2016. Phytochemicals of Moringa oleifera: a review of their nutritional, therapeutic and industrial significance. 3 Biotech, 6(2):203. DOI: https://dx.doi.org/10.1007\%2Fs13205-016-0526-3

Sarkar A, and Ghosh U. 2017. Effect of extraction temperature and technique on phenolic compounds and antioxidant activity of Tamarindus indica seeds. Research Journal of Recent sciences, 6(2): 10-15.

Sevindik M, Akgul H, Pehlivan M, Selamoglu Z. 2017. Determination of therapeutic potential of Mentha longifolia ssp. longifolia. Fresen Environ Bull, 26(7): 4757-4763.

Sevindik M. 2019. Wild Edible Mushroom Cantharellus cibarius as a Natural Antioxidant Food. Turkish Journal of Agriculture-Food Science and Technology, 7(9): 1377-1381.

Sevindik M. 2020. Antioxidant and antimicrobial capacity of Lactifluus rugatus and its antiproliferative activity on A549 cells. Indian Journal of Traditional Knowledge (IJTK), 19(2): 423-427.

Shourove JH, Zzaman W, Chowdhury RS, Hoque MM. 2020. Effect of Thermal Treatment on Physicochemical Stability and Antioxidant Properties of Locally Available Underutilized Star Fruit Juice. Asian Food Science Journal, 14(3):41-53. DOI: https://doi.org/10.9734/afsj/2020/ v14i330133

Singh JP, Kaur A, Shevkani K, Singh N. 2016. Composition, bioactive compounds and antioxidant activity of common Indian fruits and vegetables. Journal of food science and technology, 53(11):4056-66. doi: 10.1007/s13197-016-2412-8. 
Sodvadiya M, Patel H, Mishra A, Nair S. 2020. Emerging Insights into Anticancer Chemopreventive Activities of Nutraceutical Moringa oleifera: Molecular Mechanisms, Signal Transduction and In Vivo Efficacy. Current Pharmacology Reports, 6(2): 38-51. DOI: https://doi.org/10.1007/s40495020-00210-z

Sreelatha S, Padma PR. 2009. Antioxidant activity and total phenolic content of Moringa oleifera leaves in two stages of maturity. Plant foods for human nutrition, 64(4):303. DOI: https://doi.org/10.1007/s11130-009-0141-0

Tebeka T, Libsu S. 2014. Assessment of antioxidant potential of Moringa stenopetala leaf extract. Ethiopian Journal of Science and Technology, 7(2):93-104. DOI: 10.4314/ ejst.v7i2.3

Vats S, Gupta T. 2017. Evaluation of bioactive compounds and antioxidant potential of hydroethanolic extract of Moringa oleifera Lam. from Rajasthan, India. Physiology and molecular biology of plants, 23(1):239-48. DOI: https://doi.org/10.1007/s12298-016-0407-6
Vongsak B, Sithisarn P, Mangmool S, Thongpraditchote S, Wongkrajang Y, Gritsanapan W. 2013. Maximizing total phenolics, total flavonoids contents and antioxidant activity of Moringa oleifera leaf extract by the appropriate extraction method. Industrial crops and products, 44:566-71. DOI: https://doi.org/10.1016/j.indcrop.2012.09.021

Zzaman W, Bhat R, Yang TA. 2014. Effect of superheated steam roasting on the phenolic antioxidant properties of cocoa beans. Journal of food processing and preservation, 38(4):1932-38. DOI: https://doi.org/10.1111/jfpp.12166

Zzaman W, Biswas R, and Hossain MA. 2021. Application of Immersion Pre-treatments and Drying Temperatures to Improve the Comprehensive Quality of Pineapple (Ananas comosus) Slices. Heliyon: Food Science and Nutrition. (Accepted for publication). 